\title{
The Effect of Graded Doses of Ascorbic Acid on the Tissue Carnitine and Plasma Lipid Concentrations
}

\author{
Tae Youl HA, Megumi OtsuKa, and Nobuhiko ARAKAWA ${ }^{1}$ \\ Department of Food and Nutrition, Ochanomizu University, Bunkyo-ku, Tokyo 112, Japan
}

(Received March 15, 1990)

\begin{abstract}
Summary Ascorbic acid(AsA) is known to be required for the synthesis of carnitine. The present study was designed to clarify the effect of AsA on the carnitine synthesis and lipid metabolism in guinea pigs. The animals were divided into four groups, and fed AsA-free diets for three weeks. Each group was supplemented with AsA in the following doses; high-AsA group, $100 \mathrm{mg} \mathrm{AsA/day/animal;} \mathrm{control} \mathrm{group,} 5 \mathrm{mg} \mathrm{AsA}$ / day/animal; AsA-deficient group, $0.1 \mathrm{mg} \mathrm{AsA/day/animal;} \mathrm{pair-fed} \mathrm{group,}$ $5 \mathrm{mg} \mathrm{AsA} /$ day/animal. The pair-fed group was restricted to the amount of diet consumed by the AsA-deficient group. Tissue carnitine levels of the AsA-deficient group were significantly lower than not only the control group but the pair-fed group. Total cholesterol and phospholipid levels in plasma of the AsA-deficient group were found to be similar to those of the pair-fed group; however, plasma triglyceride levels were significantly higher than that of the pair-fed group. Furthermore, there was an inverse relationship between tissue AsA and plasma triglyceride levels. We concluded that carnitine synthesis and triglyceride metabolism in guinea pigs may be impaired by the decrease of tissue AsA level rather than by the insufficient food intake. It is suggested that tissue carnitine level altered by tissue AsA content affects plasma triglyceride level.
\end{abstract}

Key Words ascorbic acid, carnitine synthesis, triglyceride, guinea pig

Carnitine has an important role in the transport of long-chain fatty acid into the mitochondria matrix where $\beta$-oxidation takes place $(1,2)$. In the pathway of carnitine biosynthesis, AsA(ascorbic acid) is a cofactor required for the hydroxylation of trimethyllysine and $\gamma$-butyrobetaine $(3,4)$. It has been suggested that the lack of dietary AsA results in the decrease of tissue carnitine levels. Although several studies about the effect of AsA deficiency on carnitine biosynthesis have been reported, those results were very contradictory. Thoma and Henderson (5) observed that liver carnitine levels of scorbutic guinea pigs were significantly lower

\footnotetext{
' 河 台烈, 大塚 惠, 荒川信彦
} 
than those of control animals. In contrast, Nelson et al. (6) reported that carnitine levels of guinea pigs fed AsA-free diet for four weeks were not changed in liver and remarkably increased in plasma. These conflicting results seemed to be caused by the decrease of food intake, a concomitant symptom in the scorbutic animals.

The purpose of the present study was to clarify the effect of AsA on the carnitine synthesis and lipid metabolism. We determined AsA and carnitine contents in tissues, and lipid concentrations in plasma of the guinea pigs supplemented with graded doses of AsA and of pair-fed guinea pigs.

\section{METHODS}

Animals and diets: Twenty-four male albino guinea pigs (initial body weight of about $200 \mathrm{~g}$ ) were housed in individual cages in a light-controlled room and were acclimated for three days to the new surroundings. At the beginning of the experiment, the animals were randomly divided into four groups and, fed AsA-free diets. The animals of each group were supplemented with AsA in the following doses; high-AsA group (A), $100 \mathrm{mg}$ AsA/day/animal; control group (B), $5 \mathrm{mg}$ AsA/day/animal; AsA-deficient group (C), $0.1 \mathrm{mg} \mathrm{AsA/day/animal;} \mathrm{pair-fed} \mathrm{group}$ (D), $5 \mathrm{mg} \mathrm{AsA} /$ day/animal. AsA was dissolved in $0.9 \% \mathrm{NaCl}$ solution immediately before the administration. The animals of all groups except the pair-fed group were maintained ad libitum on AsA-free diet. The AsA-deficient group was supplemented with $0.1 \mathrm{mg} \mathrm{AsA} /$ day in order to avoid starvation. The pair-fed group was restricted to the amount of diet consumed by the AsA-deficient group. The animals were weighed daily. On day 21 of the experiment, the animals were anesthetized with Nembutal and blood samples were obtained from the aorta abdominalis. Liver, heart, kidneys, and a piece of muscle from a hind leg of each animal were removed.

Carnitine analysis: Each tissue was cut into small pieces and homogenized in 8 volumes of $6 \%$ cold $\mathrm{HClO}_{4}$. The homogenates obtained were centrifuged at $5,000 \times g$ for $10 \mathrm{~min}$ and the pellet was washed with $6 \% \mathrm{HClO}_{4}$, and centrifuged again. The supernatant of tissues and their washings were combined and kept at $-80^{\circ} \mathrm{C}$ prior to assay. The contents of carnitine in tissues were determined by the HPLC method in our previous paper (7).

AsA analysis: After extracting AsA of the tissues with 3\% metaphosphoric acid solution, the concentrations of AsA were measured by the HPLC method described previously (8).

Plasma lipid analysis: Plasma was obtained by centrifuging blood drawn into a heparinized tube at $1,500 \times g$ for $10 \mathrm{~min}$. The concentrations of plasma triglyceride, total cholesterol, and phospholipid were determined using triglyceride E-test, cholesterol C-test, and phospholipid B-test (Wako Pure Chemical Ind., Osaka, Japan), respectively.

Serum alkaline phosphatase: The serum alkaline phosphatase activity was assayed by using alkaline phospha B-test (Wako Pure Chemical Ind.) with $p$ - 
nitrophenyl phosphate as a substrate.

Statistical tests: The statistical significance of difference between the means of the two groups was determined by Student's $t$-test.

\section{RESULTS}

Figure 1 shows the changes in the average body weights of the experimental groups. AsA-deficient animals supplemented with $0.1 \mathrm{mg} \mathrm{AsA} /$ day (group C) showed a slight decrease in body weights and developed some characteristic symptoms of scurvy such as the lack of appetite after day 17. The body weights of the high-AsA group (group A) and control group (group B) increased continuously during the experimental period, while those of the pair-fed group (group D) did not change after day 17.

Serum alkaline phosphatase activity of the AsA-deficient group was markedly reduced compared with the other three groups, and, moreover, that of the pair-fed group was significantly lower than of the control group in spite of the same amount of AsA administration in both groups (Fig. 2).

Table 1 shows AsA contents in liver and kidney of guinea pigs. AsA contents in AsA-deficient guinea pigs were greatly decreased in comparison with those of the control group. AsA levels in the liver of guinea pigs supplemented with AsA $100 \mathrm{mg} /$ day (group A) were 2-3 times those of animals supplemented with AsA 5 $\mathrm{mg} /$ day (group B). However, there was no significant difference between control and pair-fed groups.

Carnitine contents in tissues are shown in Fig. 3. Liver carnitine levels of the

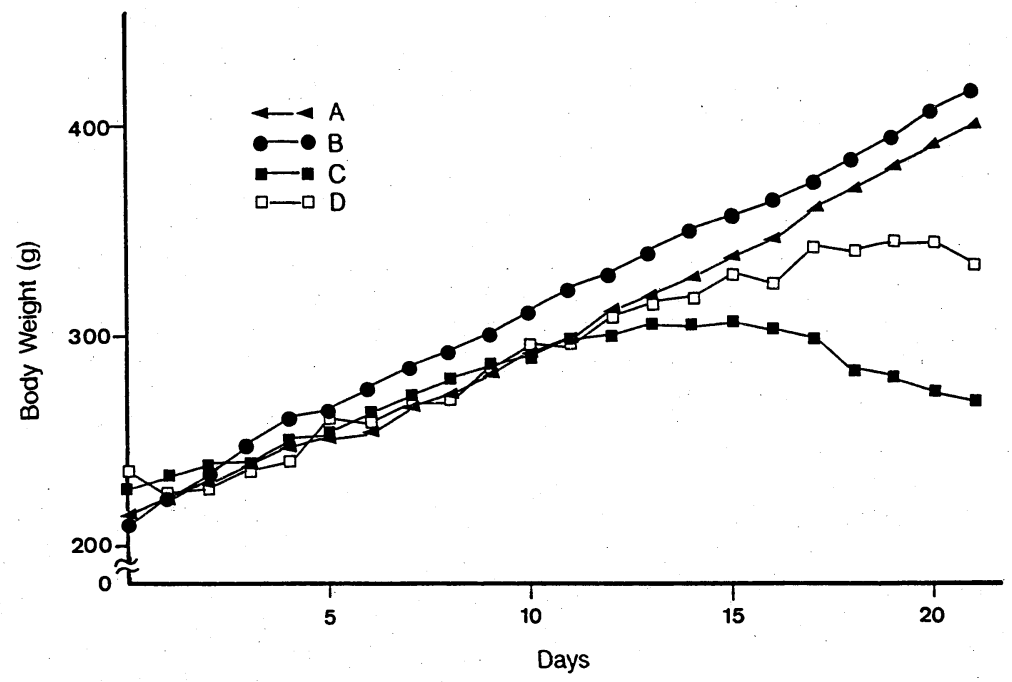

Fig. 1. Changes in body weights of guinea pigs. The animals fed AsA-free diet were supplemented with AsA in the following doses: A, $100 \mathrm{mg} \mathrm{AsA} /$ day; B, 5 $\mathrm{mg}$ AsA/day; C, $0.1 \mathrm{mg} \mathrm{AsA} /$ day; $\mathrm{D}, 5 \mathrm{mg} \mathrm{AsA} /$ day and pair-fed with group C. 


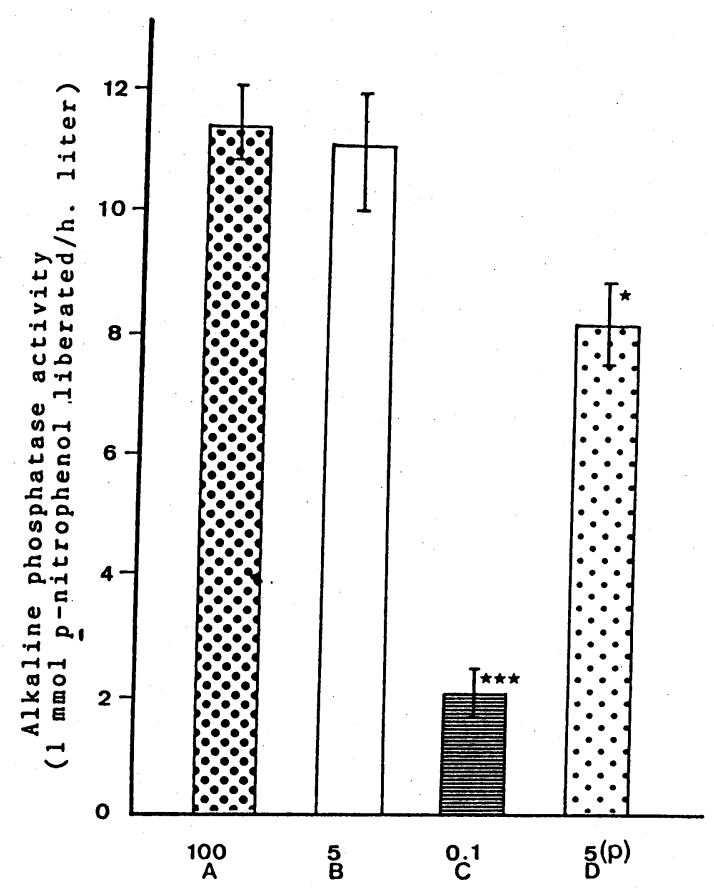

Fig. 2. Serum alkaline phosphatase activity. A, $100 \mathrm{mg} \mathrm{AsA} /$ day; B, $5 \mathrm{mg}$ AsA/day; C, $0.1 \mathrm{mg}$ AsA/day; D, pair-fed. Each column represents mean \pm SD. Significantly different from the values of group B at $p<0.05\left(^{*}\right), p<0.001(* * *)$.

Table 1. The contents of total ascorbic acid in tissues of guinea pigs.

\begin{tabular}{ccc}
\hline Group & \multicolumn{1}{c}{ Liver } & \multicolumn{1}{c}{ Kidney } \\
& \multicolumn{1}{c}{$(\mathrm{mg} / 100 \mathrm{~g}$ tissue wet wt. $)$} \\
\hline A & $10.7 \pm 1.74^{* *}$ & $5.1 \pm 0.81^{*}$ \\
B & $4.7 \pm 0.42$ & $2.9 \pm 0.26$ \\
C & $0.8 \pm 0.14^{* * *}$ & $0.6 \pm 0.14^{* * *}$ \\
D & $4.2 \pm 0.28$ & $3.4 \pm 0.20$ \\
\hline
\end{tabular}

Values are mean \pm SD. A, AsA $100 \mathrm{mg} /$ day; B, AsA $5 \mathrm{mg} /$ day; C, AsA $0.1 \mathrm{mg} / \mathrm{day}$; D, pair-fed. Significantly different from the values of group $B$ at $p<0.05\left(^{*}\right)$, $\left.\left.p<0.01{ }^{(* *}\right), p<0.001{ }^{* * *}\right)$.

AsA-deficient group were significantly lower than those of both the control and pair-fed groups $(p<0.05)$, and those of the high-AsA group were higher than those of the control group. Carnitine levels in kidney and heart of the AsA-deficient group were also significantly decreased compared with those of the control group, but the pair-fed and high-AsA groups were not affected. Carnitine levels in skeletal muscle of the AsA-deficient group had a tendency to be lower than those of both the control and pair-fed groups. 

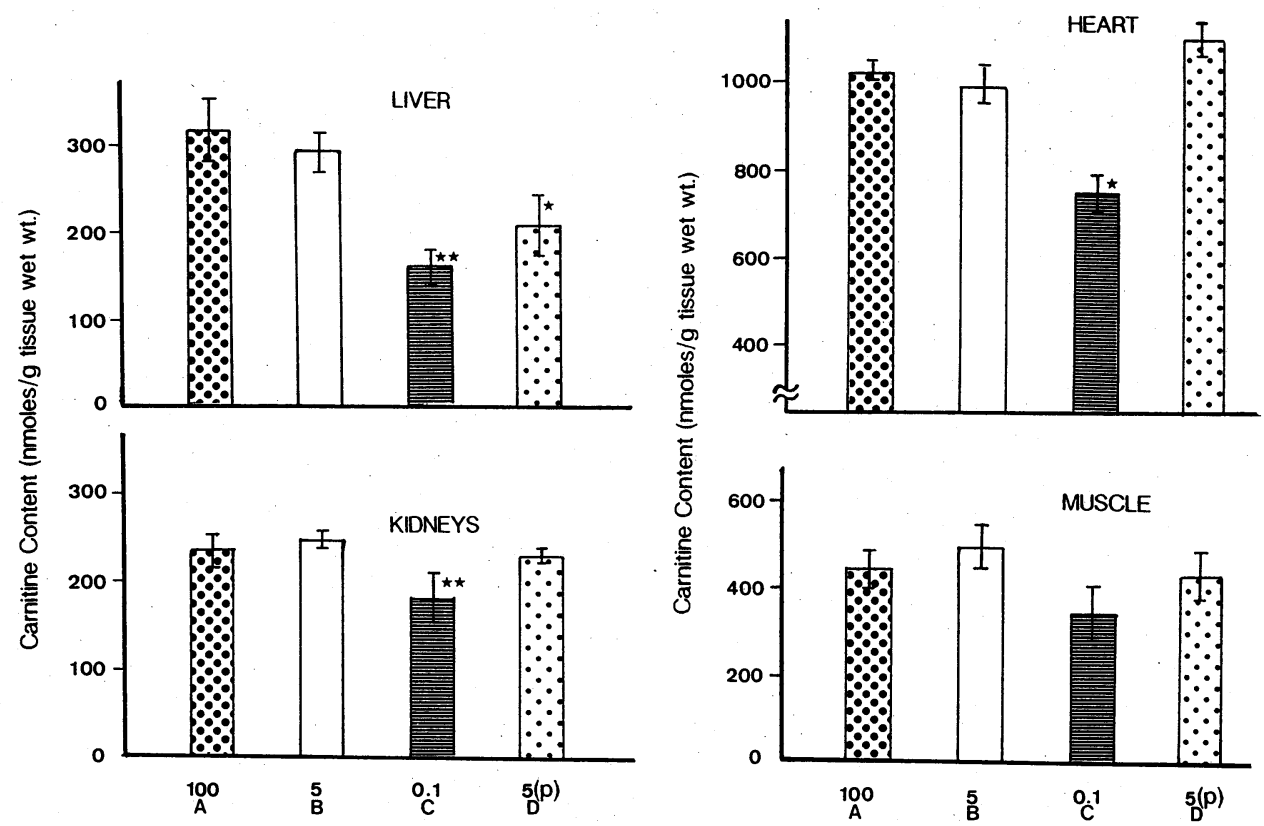

Fig. 3. Carnitine contents in tissues of guinea pigs. A, $100 \mathrm{mg} \mathrm{AsA} /$ day; B, $5 \mathrm{mg}$ AsA/day; C, $0.1 \mathrm{mg}$ AsA/day; D, pair-fed. Each column represents mean $\pm \mathrm{SD}$. Significantly different from the values of group B at $p<0.05\left(^{*}\right), p<0.01\left(^{* *}\right)$.
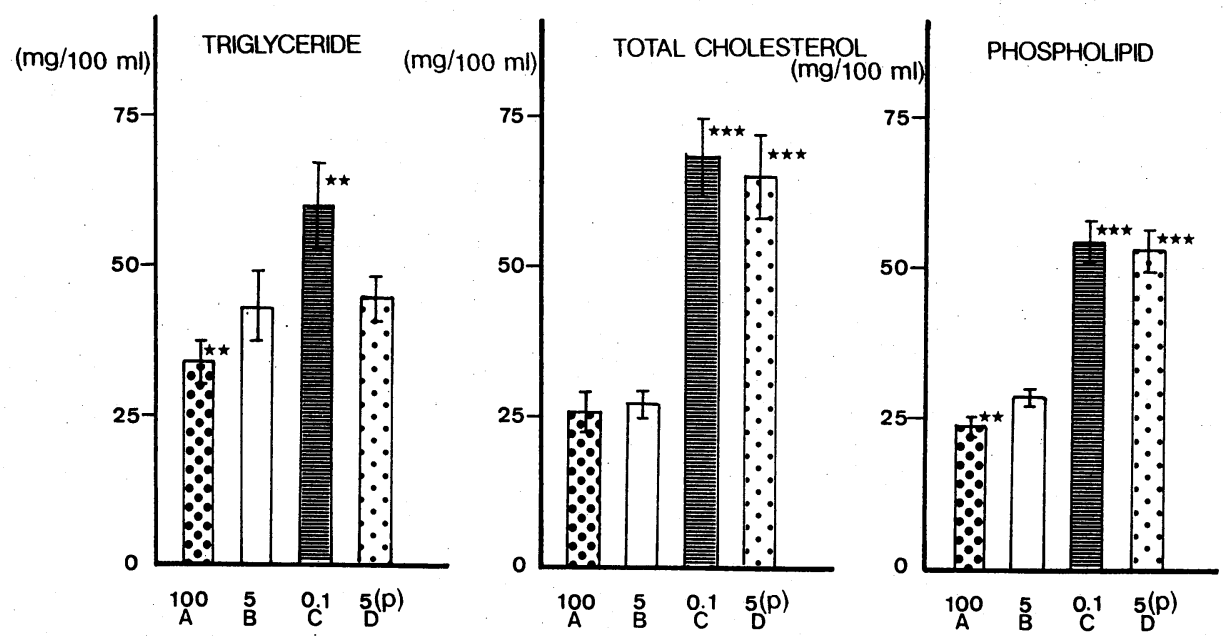

Fig. 4. Lipid concentrations in plasma of guinea pigs. A, $100 \mathrm{mg} \mathrm{AsA} /$ day; B, 5 $\mathrm{mg} \mathrm{AsA/day;} \mathrm{C,} 0.1 \mathrm{mg} \mathrm{AsA} /$ day; D, pair-fed. Each column represents mean \pm SD. Significantly different from the values of group B at $p<0.01(* *), p<0.001$ $(* * *)$. 
Figure 4 shows total cholesterol, phospholipid, and triglyceride concentrations in plasma. Plasma total cholesterol and phospholipid levels of the AsA-deficient group were closely similar to those of the pair-fed group, and much higher than those of control group. Plasma triglyceride levels of the AsA-deficient group were significantly increased compared with those of the pair-fed group, which were comparable to those of the control group.

\section{DISCUSSION}

We found that the decrease of AsA intake resulted in the lower carnitine levels in all tissues of guinea pigs. This finding is in agreement with those previously reported by Dunn et al. (9). They also observed that hydroxylation of $\gamma$-butyrobetaine to carnitine was effectively depressed in the perfused livers from AsAdeficient animals. On the contrary, it has been reported that the AsA contents in plasma and tissues of guinea pigs were not correlated with their carnitine levels. These differences could be explained in terms of the extent of the starvation, which evokes an increase in tissue carnitine levels (10), since the loss of appetite in guinea pigs fed with AsA-deficient diet leads to the starvation. In the present study, the experimental animals designated as the AsA-deficient group were supplemented with $0.1 \mathrm{mg}$ AsA/day, which was enough to avoid starvation, but food intakes in these animals were reduced after day 17 . We also examined carnitine levels of the pair-fed group in order to clarify the effect of the reduced food intake. Our results showed that carnitine contents in liver were affected by the food restriction; however, tissue carnitine levels in the AsA-deficient group were much lower than those in the pair-fed group. In other words, the decrease of tissue carnitine contents was caused by the low AsA intake rather than by the insufficient food intake. This study suggests that carnitine biosynthesis is definitely impaired by the decrease of tissue AsA level.

Furthermore, the administration of large doses of AsA was not very effective in increasing tissue carnitine contents. This result may be explained by the limited uptake of AsA into tissues. It was reported that the divided administrations of AsA per day were more useful for its absorption (11). Although the animals of the high-AsA group were supplemented with $100 \mathrm{mg} /$ day given in two doses of $50 \mathrm{mg}$ each, AsA contents in liver and kidney were only 2-3 times those of the control group.

Ginter et al. demonstrated that chronic AsA deficiency increased the concentrations of plasma and tissue cholesterol and decreased the activity of cholesterol-7 $\alpha$-hydroxylase in guinea pigs $(12,13)$. We found that the increases of total cholesterol and phospholipid concentrations in plasma of AsA-deficient animals were induced by the insufficient food intake but not by the decrease of tissue AsA levels, since these levels in plasma of the pair-fed and AsA-deficient groups were higher than those of the control group. These disagreements may be due to the difference in the experimental condition. On the other hand, we observed that 
increased triglyceride concentrations were caused by the low tissue AsA level, not by the decrease of food intake. There was an inverse correlation between the tissue AsA and plasma triglyceride levels. This result is consistent with those of Fujinami et al. (14) and Ginter et al. (15), who found increased triglyceride concentrations in AsA-deficient guinea pigs. The mechanism of hypotriglyceridemic effect of AsA has been reported to be associated with the role of AsA on lipoprotein lipase activities (16).

In the present study, tissue carnitine levels of AsA-deficient guinea pigs were significantly decreased, but plasma triglyceride concentrations were markedly increased. A similar finding has been reported by Hughes et al. (17). They also found that there were low carnitine contents and high triglyceride levels in skeletal muscle of guinea pigs supplemented with a low level of AsA, and they suggested that carnitine had a regulatory role in skeletal muscle producing energy from free fatty acid sources. Decreased carnitine levels of the AsA-deficient group may contribute to plasma triglyceride accumulation. It is considered that AsA deficiency results in decreased tissue carnitine levels; consequently, the transport of long-chain fatty acid into mitochondria may be blocked and their metabolism may be shunted toward triglyceride synthesis.

From the results obtained in this experiment, it was suggested that AsA could be responsible for the decrease of plasma triglyceride by the enhancement of carnitine biosynthesis.

\section{REFERENCES}

1) Frits, I. B. (1963): Carnitine and its role in fatty acid metabolism. Adv. Lipid Res., 1, 285-334.

2) Fritz, I. B., and Yue, K. T. N. (1963): Long-chain carnitine acyltransferase and the role of acylcarnitine derivatives in the catalytic increase of fatty acid oxidation induced by carnitine. J. Lipids Res., 4, 279-288.

3) Hulse, J. D., Ellis, S. R., and Henderson, L. M. (1978): Carnitine biosynthesis. $\beta$-Hydroxylation of trimethyllysine by an $\alpha$-ketoglutarate dependent mitochondrial dioxygenase. J. Biol. Chem., 253, 1654-1659.

4) Lindstedt, G., and Lindstedt, S. (1970): Cofactor requirements of $\gamma$-butyrobetaine hydroxylase from rat liver. J. Biol. Chem., 245, 4178-4186.

5) Thoma, W. J., and Henderson, L. M. (1984): Effect of vitamin C deficiency on hydroxylation of trimethylaminobutyrate to carnitine in guinea pig. Biochim. Biophys. Acta, 797, 136-139.

6) Nelson, P. J., Pruitt, R. E., Henderson, L. L., Jenness, R., and Henderson, L. M. (1981): Effect of ascorbic acid deficiency on the in vivo synthesis of carnitine. Biochim. Biophys. Acta, 672, 123-127.

7) Arakawa, N., Ha, T. Y., and Otsuka, M. (1989): An improved high-performance liquid chromatographic assay for the determination of free and esterified carnitine in animal tissues. J. Nutr. Sci. Vitaminol., 35, 475-479.

8) Otsuka, M., Kurata, T., Suzuki, E., Arakawa, N., and Inagaki, C. (1981): Separative

Vol. 36, No. 3, 1990 
determination of ascorbic acid and erythorbic acid in animal tissues by highperformance liquid chromatography. J. Nutr. Sci. Vitaminol., 27, 9-15.

9) Dunn, W. A., Rettura, G., Seifter, E., and Englard, S. (1984): Carnitine biosynthesis from $\gamma$-butyrobetaine and from exogenous protein-bound 6- $N$-trimethyl-L-lysine by the perfused guinea pig liver. J. Biol. Chem., 259, 10764-10774.

10) Brass, E. P., and Hoppel, C. L. (1978): Carnitine metabolism in the fasting rat. J. Biol. Chem., 253, 2688-2693.

11) Kallner, A., Hartmann, D., and Hornig, D. (1979): Steady-state turnover and body pool of ascorbic acid in man. Am. J. Clin. Nutr., 32, 530-539.

12) Ginter, E., Cerna, O., Budlovsky, J., Balaz, V., Hruba, F., Roch, V., and Sasko, E. (1977): Effect of ascorbic acid on plasma cholesterol in humans in long-term experiment. Int. J. Vitam. Nutr. Res., 47, 123-134.

13) Ginter, E., Nemec, R., Cerven, J., and Mikus, L. (1973): Quantification of lowered cholesterol oxidation in guinea pigs with latent vitamin $\mathrm{C}$ deficiency. Lipids, 8, 135141.

14) Fujinami, T., Okado, K., Sugimura, M., and Kishikawa, M. (1971): Experimental atherosclerosis with ascorbic acid deficiency. Jpn. Circ. J., 35, 1559-1565.

15) Ginter, E., and Bobek, P. (1981): The influence of vitamin C on lipid metabolism, in Vitamin C, ed. by Counsell, J. N., and Hornig, D. H., Applied Science Publishers, London and New Jersey, pp. 299-347.

16) Kotze, J. P., Matthews, M. J., and Klerk, W. A. (1974): Effect of ascorbic acid on lipoprotein lipase activity. S. Afr. Med. J., 48, 511-514.

17) Hughes, R. E., Hurley, R. J., and Jones, E. (1980): Dietary ascorbic acid and muscle carnitine ( $\beta-\mathrm{OH}-\gamma$-(trimethylamino)butyric acid) in guinea pigs. Br. J. Nutr., 43, 385-387. 